Trab. Ling. Aplic., Campinas, 44(1): 73-87, Jan./Jun. 2005

\title{
UMA ANÁLISE DOS CRITÉRIOS DOS PROFESSORES NA PREPARAÇÃO DE MATERIAL DIDÁTICO PARA CURSOS DE LÍNGUA ESTRANGEIRA DE CONTEÚDO
}

\author{
FÁBIO MADEIRA \\ (Doutorando - UNICAMP)
}

\begin{abstract}
RESUMO
Este trabalho apresenta os resultados da análise de cinco materiais didáticos utilizados para o ensino de língua estrangeira através de cursos de conteúdo. Inicio situando o leitor quanto aos conceitos e às aplicações de cursos de conteúdo e descrevo algumas experiências comentadas na literatura da área. Mostro como este tipo de curso de língua estrangeira se enquadrou nos princípios de ensino com enfoque no significado e discuto a posição dos autores que levantaram questões quanto aos aspectos mais freqüentemente escolhidos para enfoque nos cursos de conteúdo. Na seção seguinte, apresento os cursos de língua estrangeira como parte do programa de extensão cultural oferecido por uma universidade pública no estado de São Paulo, para, em seguida, discutir os materiais utilizados em cada curso e os critérios que nortearam sua preparação. Os dados foram coletados a partir das informações fornecidas pelos professores dos cursos, os quais foram também os autores dos materiais utilizados. Os resultados deixaram evidências de que, no preparo do material didático, a ênfase está posta exclusivamente no conteúdo e pode estar faltando um tratamento de aspectos lingüísticos da língua-alvo.
\end{abstract}

Palavras-chave: cursos de conteúdo, material didático, enfoque na forma.

\begin{abstract}
This paper is an analysis of the teaching materials used for five content courses to teach a foreign language. First, I will briefly define what a content course is, what their applications can be and describe some experiences. I will then show how this kind of course meets the principles of teaching a foreign language focusing on the meaning and discuss the positions of the authors who have raised some questions concerning the aspects most frequently chosen to focus on content courses. In the next section I present the courses discussed here, which are part of the cultural extension program of a public university in the state of São Paulo, Brazil. I will then discuss the material used for each course and how they were elaborated. The results have indicated that in the elaboration of the teaching materials the focus is exclusively on the content and focus on the linguistic aspects might be lacking in those materials.
\end{abstract}

Key-words: content courses, teaching material, focus on form.

\section{INTRODUÇÃO}

Já nos anos sessenta, antes do advento da abordagem comunicativa para o ensino de línguas, os cursos de conteúdo começavam a se apresentar como alternativa eficiente para o ensino de Língua Estrangeira (LE) (Leaver \& Stryker, 1989). O sucesso de uma experiência pioneira - programas de imersão em segunda língua (francês) no Canadá - despertou o 
interesse de vários programas de ensino de LE (Pica, 2002; Brinton \& Snow, 1989; Hauptman, Wesche \& Ready, 1988; Mohan, 1979). Com base no modelo daquela primeira experiência, planejadores de cursos passaram a considerar a escolha de conteúdos específicos como opção de contextualização do insumo oferecido em cursos de LE. Imbuídos dos princípios da abordagem comunicativa, aqueles profissionais encontraram nos cursos de conteúdo os requisitos básicos daquela então nova visão para o ensino de línguas: grande quantidade de insumo compreensível, relevante ao aluno e centrado no significado (no conteúdo), acima dos aspectos formais da língua-alvo.

A opção pelo maior enfoque no conteúdo, no entanto, nem sempre foi tão bem compreendida e proporcionou visões questionáveis sobre a abordagem comunicativa. Em alguns casos, tal opção levou à exclusão completa do tratamento dos aspectos lingüísticos no ensino de LE (Pica, 2002). Propus-me, com esta pesquisa, a observar como foram tratados aspectos lingüísticos na preparação de materiais didáticos elaborados para cursos de conteúdo de LE.

Este trabalho está dividido em 4 seções. Na próxima seção, ofereço uma definição de cursos de conteúdo e mostro algumas de suas aplicações. Em seguida, mostro como os cursos de conteúdo tão bem se adaptaram aos princípios das teorias de aquisição de LE. Na terceira seção, faço uma descrição geral desta pesquisa - apresento e discuto os resultados para, na última seção, fazer algumas considerações conclusivas.

\section{CURSOS DE CONTEÚDO: DEFINIÇÕES E APLICAÇÕES.}

Um curso de conteúdo pode ser definido, colocando aqui em termos básicos, como aquele que proporciona, ao mesmo tempo, conhecimento em uma determinada área acompanhado de aumento de proficiência na língua-alvo (Brinton \& Snow, 1989). Esta definição, no entanto, foi expandida para incluir os cursos de LE que possuem um assunto específico como tema central: "subject-related ESL" $e$ "ESL through subject matter teaching content-based ESL" (Graham \& Beardsley, 1986, p. 228), "sheltered courses" (Hauptman, Wesche \& Ready, 1988: 434), "subject-matter content" (Pica, 2002: 1) e "ESP" (English for Specific Purposes) - chamados no Brasil de "inglês instrumental". ${ }^{2}$ Embora alguns autores distingam ESP de cursos de conteúdo (Leaver \& Stryker, 1989; Graham \& Beardsley, 1986), Pica (2002) e Mohan (1979) incluem este tipo de curso como um curso que combina o ensino de conteúdo e de LE. Nesses cursos, o ensino da LE é destinado a alguns ambientes comunicativos específicos (Mohan, 1986) - diferente do que se chama de "inglês geral" (termo conhecido na literatura como "TENOR" - Teaching English for no Obvious Reason), isto é, o ensino da língua sem um fim específico. Aliás, não são poucos

\footnotetext{
${ }^{1}$ ESL -English as a Second language - Inglês como segunda língua

${ }^{2}$ Este conceito é ainda muitas vezes utilizado de forma inadequada no Brasil. Não é infreqüente entender "inglês instrumental" como "inglês para fins acadêmicos". Ora, inglês instrumental - para fins específicos - é o curso destinado àqueles que aprendem o idioma para um fim específico: atender telefonemas em um hotel, comunicar-se por e-mail com clientes, ler textos acadêmicos, por exemplo, ou qualquer outro fim específico.
} 
os autores e pesquisadores que postulam que inglês geral não se justifica em nenhum contexto de ensino/aprendizagem (Ramos, 1999).

Entre os diversos tipos de cursos de conteúdo, uma das possíveis distinções a se fazer seria entre aqueles que têm como objetivo central o ensino do conteúdo em si e aqueles cujo primeiro objetivo é aprimorar o nível de proficiência da LE, nos quais o conteúdo serve para a contextualização do insumo. No caso do primeiro grupo de cursos, muitas vezes o programa conta com dois profissionais: um especialista na área abordada e outro no ensino de LE. Numa experiência de ESP preparado para estudantes estrangeiros de um curso de Farmácia da Universidade de Maryland, por exemplo, o corpo docente contou com um profissional especializado na referida área e outro da área de ensino de inglês como LE (Graham \& Beardsley, 1986). No entanto, não são raras as situações nas quais o profissional da área de ensino de LE (o lingüista aplicado) adquire conhecimentos mais aprofundados da área específica através da análise de necessidades para o curso a ser ministrado (West, 1994). Já no caso do segundo grupo de cursos, aqueles que têm como objetivo central aprimorar a proficiência em LE, na maioria dos casos, o material é preparado pelo próprio professor. Entretanto, mesmo não tendo como objetivo central o ensino de um assunto específico, há também que se atentar às necessidades ou interesses dos alunos. $\mathrm{Na}$ verdade, desde o surgimento da abordagem comunicativa, não se pode conceber a preparação de material (insumo oferecido) sem que esta questão (relevância do insumo ao aluno) seja considerada (Clarke, 1989).

De tão abrangente que se tornou o termo curso de conteúdo, sua aplicação tornou-se igualmente abrangente. Como expus acima, diferentes programas são criados em diferentes universidades, para diferentes públicos; entretanto, seria um erro relacionar cursos de conteúdo exclusivamente com o ambiente universitário. Embora se possa afirmar que a contextualização é feita com maior facilidade naquele ambiente, onde cada curso, por si, já reflete o interesse do aluno, cursos de LE que visem apenas à aquisição de LE, em todas as suas habilidades, também podem ser criados com um conteúdo. Cursos de conteúdo podem ser vistos, assim, como um ensino de LE contextualizado - situação esta que, na verdade, foi um dos principais alicerces da abordagem comunicativa.

\section{CURSOS DE CONTEÚDO E AQUISIÇÃO DE LE}

As Teorias de Aquisição de Segunda Língua (termo conhecido em inglês como "SLAT". Second Language Acquisition Theories) surgiram a partir dos novos caminhos que o advento da abordagem comunicativa veio nos mostrar - novas orientações e atitudes a serem tomadas em relação ao ensino de uma LE. Foi Krashen (1982) quem deu início àquela discussão, quando postulou que um novo idioma se adquire através da exposição a grande quantidade de insumo compreensível (Hipótese do Insumo) em ambiente que ofereça condições propícias à aquisição (Hipótese do Filtro Afetivo). Dentro daquela então nova e revolucionária visão do processo de ensino e aprendizagem de LE, os cursos de conteúdo colocaram-se como opção bastante atraente. 
Se um dos pilares de sustentação da Hipótese do Insumo (Krashen, 1982) era o insumo tornado compreensível através das conexões com o conhecimento prévio, das expectativas e do contexto no qual o aprendiz está inserido, um curso de conteúdo parecia bastante apropriado. Neste contexto de aprendizagem (ou aquisição $0^{3}$ ), o insumo está sempre contextualizado, o que, por sua vez, leva o aluno a explorar seus possíveis conhecimentos prévios sobre o assunto. Além disso, professores de cursos de conteúdo fazem ajustes na linguagem (consciente e inconscientemente) com o objetivo de promover maior compreensão do tópico discutido, ou seja, tornam o insumo compreensível (Hauptman, Wesche \& Ready, 1988). No que diz respeito às condições propícias à aquisição (o filtro afetivo), outra questão relevante considerada pelas teorias de aquisição de LE, o próprio conteúdo também se coloca como fator relevante - a opção por um curso que tem um certo tema central é um fator motivador por si. Supõe-se que a escolha por um curso de conteúdo seja motivada pelo interesse do aluno e que, portanto, o insumo apresentado lhe seja interessante e relevante.

Mesmo adequando-se tão bem às novas concepções introduzidas pelas teorias de aquisição de LE, há que se observar algumas questões para garantir a eficácia do ensino de LE através de cursos de conteúdo. Se um curso de LE deve ser planejado com base no interesse dos alunos, nos dois tipos de curso de conteúdo apresentados acima (aqueles cujo objetivo é ensinar o conteúdo e aqueles que almejam o ensino da LE em si), é fundamental atentar à escolha dos aspectos lingüísticos da língua-alvo que mereçam enfoque, já que deles depende a compreensão do insumo. Poder-se-ia deduzir ainda que, no caso dos cursos de conteúdo que almejam o ensino da LE em si, os aspectos lingüísticos serão de igual importância que o conteúdo, já que se supõe que o público interessado nesse tipo de curso espera também o enfoque na LE em si. Entretanto, isso não quer dizer que se deva preparar um material a partir de itens léxico-gramaticais pré-estabelecidos. Na verdade, o caminho deve ser inverso: os itens escolhidos para receberem maior enfoque devem ser escolhidos a partir do conteúdo do material que se pretende utilizar. A escolha feita desta maneira atende, portanto, a uma questão importante: preparação de materiais didáticos e cursos centrados no aluno, isto é, no seu interesse.

Os materiais didáticos aqui discutidos são de cursos de conteúdo do segundo grupo discutidos acima - aqueles que visam não apenas ao ensino do assunto, mas têm como objetivo central o ensino da LE em si. Na literatura, costuma-se referir a esses cursos como "Subject-Matter Content" (Pica, 2002: 1) ou "Theme-Based Instruction" (Briton, Snow \& Wesche 1989: 14) - cursos temáticos.

Na discussão sobre cursos temáticos, os referidos autores ressaltam que a heterogeneidade do perfil de alunos neste tipo de curso é fator importante a ser considerado, já que não apenas as necessidades profissionais dos alunos são diferenciadas, mas seus interesses são também diversificados. Portanto, neste contexto de ensino, torna-se difícil realizar uma análise de necessidades nos moldes que propõem Hutchinson \& Waters (1987), autores que muito contribuíram para esta discussão. Na verdade, os critérios adotados para

3distingue "aquisição" de izagem" de maneira dicotômica (Scaramucci, 2001) 
a realização de uma análise de necessidades variam bastante entre diferentes autores (Wenden, 2002). Assim, o critério para a escolha dos itens lingüísticos a receberem enfoque em cursos temáticos tende a ser baseado na frequiência de ocorrência dos itens no material didático - o que não deixa de ser uma análise de necessidades.

Na discussão de cursos temáticos, Pica (2002) observou que, nesse contexto de ensino/ aprendizagem de LE, o critério de aquisição vem sendo feito baseado em dimensões globais de proficiência. Apesar de ser possível basear o critério em itens da forma, estruturas ou características do texto e do discurso, por exemplo, toma-se mais freqüentemente como base habilidades de compreensão de leitura, auditiva e produção de texto (oral e escrito). Ocorre que, tomando esse critério de aquisição, isto é, a compreensão e a produção de textos, principalmente na produção de texto oral, nem sempre se fornece evidência negativa ao aluno (Pica, 2002) e, como já foi bem discutido, sem tal evidência nem sempre é possível garantir que o insumo foi adquirido (Lightbown, 1998). Ou, como coloca VanPatten (1996), o insumo não se tornou "intake", isto é, não foi internalizado pelo aprendiz. Conforme constatou Pica, na observação de cursos de conteúdo, "os ajustes que os professores fizeram para ajudar os alunos a entender o conteúdo eram limitados em abrangência, saliência, e funcionalidade da língua-alvo, o que é considerado crucial para o desenvolvimento da interlíngua" (Pica, 2002: 1 e 2). Aliás, já foi observado que, quando se deseja enfocar um aspecto da forma da LE, a atenção do aluno deve ser direcionada. Nem sempre se pode esperar que os alunos percebam sozinhos os itens da forma, sem nenhuma assistência pedagógica (Madeira, 2003a; Doughty \& Varella, 1998; VanPatten, 1996; Schmidt, 1992; Fotos, 1998; Williams \& Evans, 1998).

O papel do ensino de aspectos lingüísticos da LE nunca deixou de estar presente na discussão de cursos de conteúdo. Já em 1979, Mohan ressaltou que apenas o uso da LE como meio de instrução não basta para garantir comunicação eficiente. Segundo o autor, a comunicação eficiente é algo que deve ser elaborado, mesmo quando se trata de comunicação em língua materna. $\mathrm{O}$ autor cita uma experiência que adaptou o modelo de alfabetização de adultos usado por Paulo Freire para ser aplicado em cursos de LE para adultos imigrantes (Medeiros, 1976, citada por Mohan, 1979): "o professor encoraja o aluno a descrever sua própria situação em relação ao tema" (Mohan, op. cit., p.:178) - ou seja, incentiva o aluno a se comunicar dentro de contexto relevante. Em sua discussão, o autor descreveu três modelos de cursos de conteúdo: 1 - combinação de ensino de LE e conteúdo, 2- ensino de LE visando o ensino de conteúdo e 3 - ensino de LE através de conteúdo. Os três modelos podem incluir atividades que visam o desenvolvimento da LE, as quais o autor classificou em três categorias: $a$ - atividades de exploração da LE (prática de estruturas gramaticais, por exemplo), $b$ - de exploração do conteúdo (questões de compreensão de um texto) e $c$ de exploração cognitiva (organizar e/ou classificar informações, por exemplo). Mohan postula que a escolha por um ou outro tipo de atividade deve ser feita de acordo com o tipo de curso que se oferece. $\mathrm{O}$ autor ressalta ainda que, em se tratando de cursos do terceiro tipo exposto acima (ensino de LE através do conteúdo), os quais mais se aproximam daqueles analisados nesta pesquisa, é essencial ter-se em mente também o ensino de aspectos lingüísticos da LE: "o ensino de conteúdo precisa ter algumas das características do bom ensino de línguas para que seja eficiente” (Mohan, 1979: 175). 
MADEIRA - Uma análise dos critérios dos professores...

Tendo em vista essa realidade e o fato de ser integrante de um grupo de pesquisa envolvido diretamente com a preparação de material didático para cursos de conteúdo, propus-me a investigar quais critérios nortearam os professores na preparação de material didático para os cursos aqui discutidos.

Passo abaixo a descrever a pesquisa aqui apresentada.

\section{DESCRIÇÃO DA PESQUISA}

\subsection{Cursos observados}

Os cursos analisados neste trabalho foram parte do programa de extensão de uma universidade pública de São Paulo. Tratava-se de cinco cursos intensivos - um período de 2 semanas com 3 horas de aulas diárias. Os cursos oferecidos foram: 1- Estados Unidos: A Construção de Uma Cultura, 2- História do Reino Unido, 3- Estudo Comparativo das Histórias dos Estados Unidos e do Brasil, 4- Língua e Cultura Brasileiras para Falantes de Espanhol e 5- Linguagem do Método em Atividades Comunicativas p/ o Ensino de Língua Estrangeira. O curso que tinha como tema a construção da cultura estadunidense tratou de alguns dos aspectos mais relevantes da história dos EUA, desde o período précolonial até o movimento hippie, e procurou relacioná-los com a cultura construída daquele país. O curso de história do Reino Unido teve maior enfoque na história da realeza inglesa e nas conquistas daquele reino, enquanto o curso que comparou aspectos culturais do Brasil e dos Estados Unidos enfocou as diferenças geográficas e das colonizações dos dois países. O curso de português para falantes de espanhol teve como tema central a cultura brasileira, considerando suas características e sua relação com outras culturas, que, conjuntamente, formam a identidade latino-americana. $\mathrm{O}$ curso cujo tema foi a abordagem comunicativa de ensino de línguas teve como objetivo investigar e interferir no imaginário dos professores de inglês acerca daquela abordagem de ensino de LE. Todos os cinco cursos tinham como objetivo central o ensino de LE.

\subsection{Materiais}

Os materiais didáticos analisados foram compostos pelos professores responsáveis pelos cursos. São livros preparados com textos e ilustrações sobre o assunto de cada curso e foram entregues aos alunos no primeiro dia de aula, com apenas uma exceção. No curso Estudo Comparativo das Histórias dos Estados Unidos e do Brasil o material didático era fornecido aos alunos a cada aula.

\subsection{Objetivos da pesquisa}

Meu objetivo com esta pesquisa foi observar os critérios que nortearam os professores na preparação do material didático de cursos de conteúdo de LE. Procurei observar, mais 
especificamente, se, além do ensino do conteúdo, foram também observados e incluídos nos materiais didáticos quaisquer aspectos lingüísticos da LE escolhidos para enfoque.

\subsection{Metodologia}

As informações acerca dos materiais didáticos e dos cursos foram obtidas a partir de uma combinação de dois instrumentos: questionário aplicado ao professor e análise do material didático por ele criado. $\mathrm{O}$ questionário aplicado foi dividido em duas partes. A primeira teve como objetivo investigar se, na preparação do material, o professor escolheu algum item da forma que fosse freqüente nos textos e se, conseqüentemente, incluiu explicações e/ou atividades de exploração da $\mathrm{LE}^{4}$ naquele material. A segunda parte continha questões relacionadas com a atuação dos alunos em sala de aula - se suas dúvidas mais frequientes envolviam o conteúdo em si ou aspectos lexicais e gramaticais da LE (vide anexo).

Os professores de cada curso foram por mim conscientizados sobre os objetivos e os procedimentos da pesquisa e concordaram em fornecer os dados para a sua realização. Em conversa com cada um deles, individualmente, apresentei as diferentes etapas da minha investigação, apliquei o questionário e pedi uma cópia do material utilizado em seus cursos para a minha análise. Todos os cinco professores cederam o material para a análise.

\section{4 - RESULTADOS}

Os dados obtidos através do questionário mostraram que o enfoque nos materiais de todos os cursos observados foi, quase exclusivamente, no conteúdo, isto é, no assunto tratado em cada curso.

O primeiro quadro apresentado abaixo (figura 1) mostra as respostas dos professores às perguntas com respeito à preparação do material. Cada coluna mostra as respostas dos professores/autores do material didático às perguntas do questionário. Visando facilitar a tarefa do leitor, a apresentação do quadro é antecedida pela explicação mais detalhada do que se procurou verificar com cada pergunta do questionário:

Colunas do quadro:

$1^{\text {a }}$ coluna - mostra se houve atividades em relação ao conteúdo do curso;

$2^{\mathrm{a}}$ coluna - indica os aspectos considerados pelo professor na correção dos textos produzidos pelos alunos: conteúdo, gramática ou ortografia;

$3^{a}$ coluna - mostra o tipo de atividade proposta, escolhida entre quatro tipos de atividades mais freqüentemente utilizadas em materiais de cursos de extensão (Mohan, 1979; Pica, 2002): a) perguntas e respostas baseadas em um texto lido anteriormente, b)

\footnotetext{
${ }^{4}$ Entende-se aqui "exploração de LE” como apresentado acima (Mohan, 1979): enfoque em um item gramatical da LE (prática de estruturas gramaticais, por exemplo).
} 
MADEIRA - Uma análise dos critérios dos professores...

composição de pequenos textos, c) questões relacionando o assunto com a experiência pessoal e/ou conhecimento e d) experiência de vida do aluno;

$4^{\mathrm{a}}$ coluna - indica se foram incluídas no material didático atividades visando a prática de algum aspecto lingüístico (do léxico ou gramatical);

$5^{\text {a }}$ coluna - indica se foram incluídos exercícios de sistematização naquele material.

\begin{tabular}{|c|c|c|c|c|c|}
\hline CURSOS & $\begin{array}{c}\text { Atividades } \\
\text { relacionadas ao } \\
\text { conteúdo }\end{array}$ & $\begin{array}{c}\text { Aspectos } \\
\text { considerados } \\
\text { na correção }\end{array}$ & $\begin{array}{c}\text { Tipos de } \\
\text { atividades }\end{array}$ & $\begin{array}{c}\text { Atividades } \\
\text { enfocando } \\
\text { algum aspecto } \\
\text { lingǘstico }\end{array}$ & $\begin{array}{c}\text { Exercícios de } \\
\text { sistematização }\end{array}$ \\
\hline $\begin{array}{c}\text { Construção da } \\
\text { cultura americana }\end{array}$ & $\operatorname{sim}$ & os 3 aspectos & $\begin{array}{c}\text { composição de } \\
\text { pequenos } \\
\text { textos }\end{array}$ & não & não \\
\hline $\begin{array}{c}\text { História do Reino } \\
\text { Unido }\end{array}$ & $\operatorname{sim} 3$ aspectos & $\begin{array}{c}\text { relacionadas } \\
\text { com a } \\
\text { experiência do } \\
\text { aluno }\end{array}$ & não & não \\
\hline $\begin{array}{c}\text { Comparação da } \\
\text { história americana } \\
\text { e brasileira }\end{array}$ & $\operatorname{sim}$ & $\operatorname{conteúdo~}$ & $\begin{array}{c}\text { perguntas e } \\
\text { respostas } \\
\text { sobre um texto }\end{array}$ & não & não \\
\hline $\begin{array}{c}\text { Língua e Cultura } \\
\text { brasileiras para } \\
\text { falantes de } \\
\text { espanhol }\end{array}$ & $\operatorname{sim}$ & conteúdo & $\begin{array}{c}\text { relacionadas } \\
\text { com a } \\
\text { experiência do } \\
\text { aluno }\end{array}$ & não & não \\
\hline $\begin{array}{c}\text { Atividades } \\
\text { Comunicativas } \\
\text { para o Ensino de } \\
\text { Língua } \\
\text { Estrangeira }\end{array}$ & $\operatorname{sim}$ & conteúdo & $\begin{array}{c}\text { relacionadas } \\
\text { com a } \\
\text { experiência do } \\
\text { aluno }\end{array}$ & não & \\
\hline
\end{tabular}

Figura 1: Critérios utilizados na preparação do material didático

O quadro acima mostra que a preocupação predominante dos professores na preparação do material didático foi com o conteúdo. Não houve atividades enfocando qualquer aspecto lingüístico nem tampouco qualquer tipo de exercício de sistematização. Observa-se também que, embora o critério para a correção dos textos produzidos pelos alunos tenha variado entre os professores, a maior parte deles optou pela não correção dos aspectos lingüísticos da LE. Os resultados indicaram ainda que não houve observação aos aspectos léxicogramaticais da LE recorrentes nos textos (uma análise de necessidades para escolha de aspectos da LE a receberem maior atenção) nem tampouco atividades de exploração da LE (explicações e/ou exercícios) enfocando tais aspectos. Predominaram, naqueles materiais, atividades de exploração do conteúdo e de exploração cognitiva, como mostra o extrato abaixo. 
Trabalhos em Lingüística Aplicada 44(1) - Jan./Jun. 2005

Atividades contidas no material didático do curso USA: The Building of a Culture :

a- atividade de exploração do conteúdo (baseada em uma leitura anterior)

Draw a time line of the discovery of America.

Example:

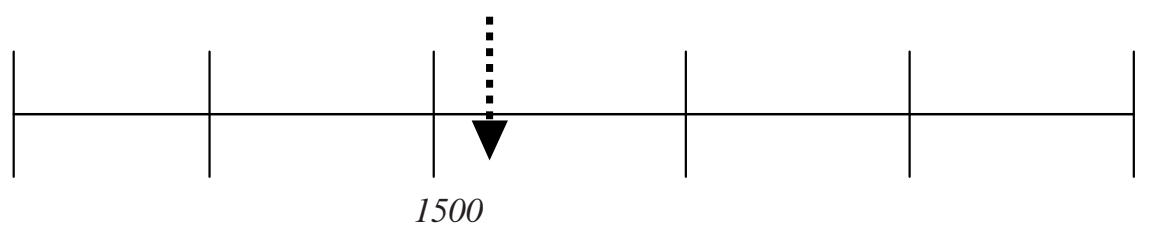

Columbus

b- atividade de exploração cognitiva (organizar informações e estabelecer relações com a experiência/conhecimento de mundo do aluno)

$b$ - How was the colonization in the United States different from the colonization in Brazil? Think of some characteristics of the American people and start a group discussion about them. What is the relationship between the way the United States was colonized and the way the American people are today?

As questões abaixo foram formuladas a partir de um texto que descrevia as condições sanitárias das caravelas portuguesas em viagem entre Brasil e Portugal.

Atividade do material didático do curso Língua e Cultura Brasileiras para Falantes de Espanhol

a- Quais eram os argumentos do discurso médico-científico e do discurso moralizador da igreja sobre o banho, no século XVI?

b- Você consegue se imaginar viajando nas caravelas do século XVII? Por quê?

c- E na sua cultura, como é visto o banho? E no Brasil?

A segunda parte do questionário buscou investigar o que ocorria em sala de aula. Veja abaixo a descrição das três colunas do quadro:

$1^{\text {a }}$ coluna - apresenta as mais frequientes questões levantadas pelos alunos (sobre conteúdo, vocabulário ou sobre a forma), apresentadas em ordem de maior freqüência;

$2^{\mathrm{a}}$ coluna - correção pelo professor da produção oral dos alunos nas discussões;

$3^{\text {a }}$ coluna - tratamento planejado de aspectos léxico-gramaticais durante as aulas; 
MADEIRA - Uma análise dos critérios dos professores...

\begin{tabular}{|c|c|c|c|}
\hline CURSOS & $\begin{array}{c}\text { Maior } \\
\text { freqüência das } \\
\text { perguntas dos } \\
\text { alunos }\end{array}$ & $\begin{array}{c}\text { Correção da } \\
\text { produção oral } \\
\text { dos alunos }\end{array}$ & $\begin{array}{c}\text { Planejamento para ocorrência de } \\
\text { questões sobre algum item } \\
\text { lingǘstico em sala de aula }\end{array}$ \\
\hline $\begin{array}{c}\text { Construção da Cultura } \\
\text { Americana }\end{array}$ & $\begin{array}{c}\text { Vocabulário } \\
\text { Conteúdo } \\
\text { Gramática }\end{array}$ & $\begin{array}{c}50 \% \\
\text { das vezes }\end{array}$ & $\begin{array}{c}\text { Sim, quando observada a } \\
\text { necessidade }\end{array}$ \\
\hline História do Reino Unido & $\begin{array}{c}\text { Conteúdo } \\
\text { Vocabulário } \\
\text { Gramática }\end{array}$ & Sempre & não \\
\hline $\begin{array}{c}\text { Comparação da história } \\
\text { americana e brasileira }\end{array}$ & $\begin{array}{c}\text { Conteúdo } \\
\text { Vocabulário } \\
\text { Gramática }\end{array}$ & $\begin{array}{c}\text { Menos de 20\% } \\
\text { das vezes }\end{array}$ & não \\
\hline $\begin{array}{c}\text { Língua e Cultura } \\
\text { brasileiras para falantes de } \\
\text { espanhol }\end{array}$ & $\begin{array}{c}\text { Conteúdo } \\
\text { Vocabulário } \\
\text { Gramática }\end{array}$ & $\begin{array}{c}50 \% \\
\text { das vezes }\end{array}$ & Sim, quando observada a \\
necessidade
\end{tabular}

Figura 2: Atuação de professores e alunos em sala de aula

Observa-se que, no ponto de vista dos professores, as mais freqüentes perguntas dos alunos, em quatro dos cursos, eram relacionadas ao conteúdo, em um dos cursos eram relacionadas ao vocabulário e, nos cinco cursos, as perguntas menos freqüentes eram sobre gramática. Quanto à correção da produção oral dos alunos, embora tenha havido variação entre os professores na frequiência da correção, todos o faziam. Dois professores afirmaram ainda ter procurado, nas discussões, levar os alunos a produzir LE contendo os itens nos quais apresentavam dificuldades.

Passo, a seguir, a uma breve discussão dos resultados apresentados.

\section{DISCUSSÃO}

A observação dos materiais didáticos dos cursos temáticos aqui discutidos leva a constatações semelhantes àquelas feitas por Pica (2002): o critério de aquisição de LE utilizado em cursos de conteúdo é, geralmente, baseado em dimensões globais de 
proficiência - compreensão de leitura, auditiva e produção de texto oral e escrito. De acordo com as respostas do professores ao questionário aplicado e com a observação dos materiais, não houve, em nenhum dos materiais didáticos analisados, tratamento de quaisquer aspectos lingüísticos da LE.

A análise feita neste trabalho, no que diz respeito à preparação do material didático, reflete o que se chamou de posição zero - posição dos autores e pesquisadores da área de ensino de LE que defendem que o ensino da forma tem efeito nulo no processo de aquisição de LE (Foto \& Ellis, 1991). Reflete, acima de tudo, uma tendência, por parte dos professores, à posição que Ellis (1985) chamou de não-interface aquisição-aprendizagem isto é, parecem ter convicção de que o insumo compreensível e a comunicação bastam para a aquisição da forma. Entretanto, esta posição vem, desde a última década, sendo questionada (Madeira, 2003a; Doughty \& Williams, 1998). Warschauer (1998) chamou de "visão póscomunicativa" de ensino aquela que adota todos os preceitos da abordagem comunicativa, porém, inclui o enfoque na forma, visando, desta maneira, proporcionar a percepção da forma e da função para a qual ela é utilizada.

Apesar de os materiais didáticos terem refletido uma postura de não-interface aquisição/aprendizagem por parte dos professores, a interação professor-aluno em sala de aula parece refletir tendência à interface fraca, isto é, aqueles profissionais parecem crer que a intervenção pedagógica para a forma pode auxiliar no processo de aquisição. Todos os professores afirmaram, através de suas respostas ao questionário, ter feito correções na produção oral dos alunos (vide figura dois), prática essa que, segundo alguns autores, contribui para o processo de aquisição (Doughty \& Varella, 1998; Lightbown, 1998; VanPatten, 1996 e Madeira, 2003a; Madeira, 2003b). Além disso, o fato de dois dos professores terem procurado levar os alunos a produzir oralmente as estruturas nas quais apresentaram dificuldades pode ser encarado como um tipo de rotinização - o que Mohan (1979) incluiu como atividade de exploração da LE e afirmou ser parte integrante dos cursos de conteúdo de LE. É importante ressaltar, entretanto, que os dados aqui apresentados sobre a atuação de professores e alunos em sala de aula foram coletados através de questionário e o uso apenas desse instrumento nem sempre garante resultados confiáveis (Kern, 1995). Estes dados estão sendo aqui utilizados apenas como informações complementares. Portanto, não se pode concluir que as respostas dos professores reflitam fielmente o que ocorreu em sala de aula. Para uma investigação mais profunda nesse sentido seria necessário o uso de outro instrumento, como a observação da sala de aula.

A maior ocorrência de perguntas dos alunos em relação ao conteúdo e ao vocabulário, segundo as respostas dos professores ao questionário, pode ser analisada sob dois aspectos. Primeiro, demonstra interesse por parte dos alunos na compreensão do conteúdo. Pressupõese que, ao escolherem um determinado curso de conteúdo (entre os cinco disponíveis), o assunto daquele curso seja a eles relevante e/ou interessante. Por outro lado, poderia indicar também falta de direcionamento, por parte dos professores, da atenção dos alunos aos aspectos formais da LE. Como já foi constatado, não se pode presumir que a atenção à forma ocorra apenas a partir da percepção dos alunos - nem sempre se pode esperar que eles atentem aos itens da forma sem nenhuma assistência pedagógica (Madeira, 2003b; 
MADEIRA - Uma análise dos critérios dos professores...

Doughty \& Varella, 1998; VanPatten, 1996; Schmidt, 1992; Fotos, 1998; Williams \& Evans, 1998). Se, como expus acima, os cursos de conteúdo aqui discutidos são do tipo "temático", os quais têm como objetivo não apenas o ensino do assunto, mas também o ensino da LE em si (Pica, 2002; Briton, Snow \& Wesche 1989), um maior enfoque na forma poderia ser justificável. Poder-se-ia concluir ainda que o não tratamento de quaisquer aspectos formais da LE nos livros didáticos aqui analisados seja resultado da não atenção, por parte dos professores, aos aspectos da forma da LE mais recorrentes nos textos de cada material. Uma observação mais profunda daqueles aspectos da LE nos textos possivelmente resultaria na escolha de alguns itens gramaticais que merecessem enfoque - uma análise de necessidades.

Vale ressaltar, para encerrar esta discussão, que o tratamento de aspectos da forma da LE, tanto no material didático quanto em sala de aula, não tira o caráter comunicativo de uma abordagem - como bem coloca Scaramucci (2001), abordagem comunicativa não significa exclusão do tratamento do aspecto formal da LE. Um curso de conteúdo já é, por si, bastante comunicativo - é inteiramente elaborado embasado em um conteúdo, ou seja, tem como base o significado. Portanto, incluir também o tratamento à forma no processo de ensino/aprendizagem de LE embasado nos princípios da abordagem comunicativa seja através de sistematizações (paradas breves para explicações da forma) ou de rotinizações (prática de estruturas) - é justificável (Doughty e Williams, 1998).

\section{CONSIDERAÇÕES FINAIS}

O objetivo deste artigo foi apresentar os resultados de uma pesquisa sobre os critérios que nortearam os preparadores de materiais didáticos para cinco cursos de conteúdo do tipo temático, isto é, que têm como objetivo o ensino da LE através de um determinado conteúdo.

Se, por um lado, esse tipo de curso veio oferecer uma alternativa atraente para o ensino de um novo idioma dentro de um contexto que prioriza o significado, por outro, pode levar ao não tratamento de aspectos formais da língua-alvo, parte integrante dos cursos daquele tipo (Mohan, 1979; Pica, 2002).

Os resultados deste estudo indicam que, no preparo dos materiais didáticos aqui analisados, a atenção foi dada exclusivamente ao conteúdo - os aspectos formais da línguaalvo não foram tratados. Isso reflete, de certa maneira, a constatação, feita por Pica (2002), de que, em cursos temáticos de LE, o critério de aquisição vem sendo feito pautado em dimensões globais de proficiência, com base em habilidades de compreensão e de produção de texto (oral e escrito), sendo quase nunca tratados os aspectos formais da língua-alvo.

É importante ressalvar que, embora os livros didáticos aqui analisados não tratassem dos aspectos formais da língua, nas respostas ao questionário, todos os professores/autores dos livros afirmaram ter feito correções na produção oral dos alunos. Dois professores disseram ainda ter tratado de aspectos formais em sala de aula sempre que verificada a necessidade. Entretanto, como não houve observação da sala de aula e este não era o 
objetivo desta pesquisa, essas afirmações não puderam ser formalmente consideradas. Fica aqui a sugestão para uma futura investigação.

\section{REFERÊNCIAS BIBLIOGRÁFICAS}

BRINTON, D., SNOW, M. A., WESCHE, M. (1989). Content-based second language instruction. New York, Newbury House.

CLARKE, F. D. (1989). State of the Art article, “Communicative theory and its influence on materials production", Language Teaching. April. p. 73-86.

DOUGHTY C. and VARELLA E. (1998). Communicative focus on form. In Doughty C. \& Williams, J. Focus on form in second language classroom. p. 114-138. Nova Iorque: Cambridge University Press.

DOUGHTY C. e WILLIAMS, J. (1998). Focus on form in second language classroom. Nova Iorque: Cambridge University Press.

ELLIS, R. (1985). Understanding second language acquisition. Oxford: Oxford University Press.

FOTOS, S. (1998). Shifting the focus from forms to form in the efl classroom. ELT Journal,vol. 52/4.

GRAHAM J. G. \& BEARDSLEY, R. S. (1986). English for specific purpose: content, language, and communication on a pharmacy course model. TESOL Quarterly, 20, p.227-245.

HAUPTMAN, P. C., WESCHE, M. \& READY, D. (1988). Second-language acquisition through subjectmatter learning: A follow-up study at the University of Ottawa. Language Learning, 38. p. 433-461.

HUTCHINSON T. \& WATERS A. (1987). English for specific purposes. Cambridge: Cambridge University Press.

KERN, G. R. (1995). Students' and teachers' beliefs about language learning. Foreign Language Annals, vol. 28, nº 1. p. 71-92.

KRASHEN, S. (1982). Principles and practice in second language acquisition. Oxford, Pergamon.

LEAVER, B. L., \& STRYKER, S. B. (1989). Content-based instruction for foreign language classroom. Foreign Language Annals, 22, p. 269-275.

LIGHTBOWN, P. M. (1998). The importance of timing in focus on form. In: Doughty, C. \& Williams, J. (org.) Focus on form in classroom second language. Nova Iorque: Cambridge University Press.

MADEIRA, F. (2003a). O ensino da forma — retomada a discussão entre os pesquisadores da área de aquisição de língua estrangeira". Trabalhos em Lingüística Aplicada $n^{o}$ 41, p. 105-118. Disponível em: http:/ madeira.sites.uol.com.br

MADEIRA, F. A (2003b). Comunicação em língua estrangeira mediada pelo computador: o impacto na precisão. Revista Humanidades, $n^{\circ} 2$ Série Letras, ${ }^{\circ}$ 1. p. 49 67. Disponível em: http://madeira.sites.uol.com.br

MOHAN, B. A. (1979). Relating language teaching and content teaching. TESOL Quarterly, vol. 13, $n^{\circ} 2$. 
MADEIRA - Uma análise dos critérios dos professores...

PICA, T. (2002). Subject-matter content: how does it assist the interactional and linguistic need of classroom language learners? - The Modern language Journal, 86, I.

RAMOS, R. (1999). Palestra dada em aula do curso de Inglês para fins específicos - PUCSP.

SCARAMUCCI, R. M. (2001). Comunicação particular no IEL - Instituto de Estudos da Linguagem, UNICAMP

SCHMIDT, R. (1992). Psychological mechanisms underlying second language fluency. Studies in Second Language Acquisition, 14.

VANPATTEN, B. (1996). Input processing and grammar instruction in second language acquisition. New Jersey: Ablex Publishing Corporation.

WARSCHAUER, M. (1998). Interaction, negotiation and computer-mediated learning. In: M. Clay (Ed.), Practical applications of educational technology in language learning. Lyon, France: National Institute of Applied Science.

WENDEN, A. L. (2002). Learner development in language learning. Applied Linguistics, 23/1, p. 32-55.

WEST, R. (1994). Needs analysis in language teaching. Language Teaching, Janeiro, p. 1-19.

WILLIAMS, J. \& EVANS, J. (1998). What kind of focus and on which forms? In: Focus on form in classroom second language acquisition. Doughty, C. \& Williams, J. (org.). Cambridge: Cambridge University Press. 


\section{Apêndice}

Questionário aplicado aos professores

- Houve, na apostila, exercícios preparados para os alunos? ( $) \operatorname{sim} \quad(\quad)$ não

- Como são os exercícios em seu material? Nos itens assinalados, escreva ao lado a freqüência (em porcentagem) da ocorrência. No exemplo, o número $40 \%$ indica que, dos exercícios da apostila/ livro, $40 \%$ eram perguntas a serem respondidas após a leitura de um texto. Escreva nas linhas abaixo qualquer informação adicional que você creia ser interessante constar sobre se material. Caso tenha havido outro tipo de exercício, procure descrevê-lo.

Exemplo: (sim ) perguntas e respostas baseadas em um texto lido anteriormente $20 \%$

( ) perguntas e respostas baseadas em um texto lido anteriormente

( ) composição de pequenos textos

( ) questões pedindo relação de um certo assunto com a experiência pessoal e/ou conhecimento e experiência de vida do aluno

( ) em cada exercício havia uma relação com algum aspecto da língua em si (do léxico ou gramatical)

- A solução do algum exercício envolvia o uso de algum item previamente escolhido?

( ) $\operatorname{sim}($ ) não

- Ao preparar as unidades de seu material, você tinha em mente alguns aspectos da língua a serem tratado em cada unidade? ( ) sim ( ) não

- Quais?

- Havia nos texto grande quantidade de exemplos do item que você enfocou (caso tenha havido enfoque)? ( ) sim ( )não

- Nas perguntas feitas pelos alunos, o assunto mais freqüente foi

( ) assunto discutido ( ) item lexical ( ) item gramatical

(numere de 1 a 3, de acordo com a frequiência das perguntas de cada assunto, sendo que o número 3 é para a maior ocorrência):

Nas discussões abertas, com o grupo todo, os alunos eram corrigidos durante a produção oral?

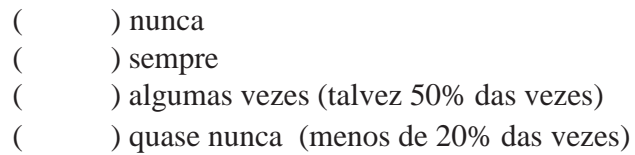

